\title{
Religiáo, Gênero e Sociedade: Ordem romana, ordem sagrada
}

\author{
Claudia Beltráo da Rosa \\ Universidade Federal do Estado Rio de Janeiro
}

Se é lícito aos poetas segredar com os deuses, Se luzes, qual se crê, nos vêm deles, Uma dúvida, ó [Marte] Gradivo, resolva-me:

Sendo tu viril por excelência, A que vêm matronas frequentar tuas festas? (Ovídio, Fasti, III, 167-170)

Recentemente, o interesse de historiadores pelo estudo dos discursos e das ideologias sobre a masculinidade e a feminilidade em diferentes épocas e em diferentes esferas das atividades sociais foi despertado. Corpos masculinos e corpos femininos são construídos e modelados de modo variado conforme as épocas, as modas, as pressóes sociais e as atividades e características que lhes são atribuídas. O olhar dos historiadores se volta para as açóes e os corpos dos indivíduos e os modos pelos quais se constituem e se alteram no tempo e no espaço, e percebe que homem e mulher não são termos neutros, nem descritivos. São termos utilizados em contextos precisos, nos quais uma diferença e, muitas vezes, uma hierarquia são sublinhadas. Para a pesquisa histórica, é importante observar os contextos específicos nos quais representaçóes do que é ser homem e do que é ser mulher, e daquilo que se espera de homens e de mulheres nas sociedades, são veiculadas e reiteradas, agindo sobre os comportamentos, as aparências, as vestimentas, os gestos, as vozes, as profissóes, as atribuiçóes, as distinçôes e todo tipo de atividade física, social, sexual etc., tendo em vista que este tipo de abordagem:

... exige levar em conta, em toda sociedade, a análise dos papeis assumidos pelos dois sexos, e estudar a articulação, própria a cada cultura, desses papeis e deles abstrair todas as consequências para a interpretação global do sistema social ${ }^{1}$.

\footnotetext{
${ }^{1}$ Pauline, SCHMITT-PANTEL. Aithra et Pandora. Femmes, Genre et Cité dans la Grèce antique.
} 
A historiografia, contudo, é ainda resistente a abordagens deste tipo, e uma das "acusaçóes" mais frequentes contra análises que incluem elementos dos estudos de gênero é a de ser pautada pelo anacronismo. Acreditamos ser salutar a pergunta pela pertinência de uma abordagem de gênero a um material e a uma sociedade táo distantes de nós no tempo, no espaço e na experiência como a romana. É certo que nenhuma prática, nenhuma pesquisa, nenhuma escrita da história estão isoladas do contexto sociocultural do qual emergem, pois que a história é uma operação resultante da relação entre um lugar, um ofício, uma literatura, e procedimentos específicos de análise ${ }^{2}$. Uma historiografia ainda pautada pela centralidade dos documentos textuais acusa, também, o fato de que os textos que nos chegaram da antiguidade foram produzidos majoritariamente por homens, mas isto não é exatamente uma dificuldade. Mesmo que utilizemos exclusivamente em nossas pesquisas corpora textuais - o que não cremos aconselhável em pesquisas sobre sociedades da antiguidade -, uma autoria "feminina" não garantiria a priori que o conteúdo fosse diferente, posto que a identidade sexual e de gênero não é natural, e a maioria das pessoas veicula os conteúdos do sistema de gênero de sua época e lugar de forma acrítica. A dificuldade propriamente dita está no fato de que os documentos que chegaram até nós veiculam majoritariamente um discurso normativo, independentemente do sexo de quem o escreveu, e a dificuldade é ideológica: a maior parte de nossa documentação textual - e boa parte da imagética e do registro arqueológico - pode ser definida como "fontes autorizadas" pelo poder e pela ideologia dominante.

Certamente, há o risco do anacronismo, mas qual é a abordagem passada ou atual da história cujo objeto de pesquisa foi ou é pautado por questôes atemporais ou ilocalizadas? Cremos que não há a necessidade de pontuarmos o fato de que as questóes e os objetos da pesquisa histórica são, quaisquer que sejam, temporais e localizados; são sempre do seu presente. Desse modo, a inclusão de elementos dos estudos de gênero na pesquisa sobre sociedades antigas não é mais nem menos anacrônica do que quaisquer outras

Paris: L'Harmattan, 2009, p.25.

${ }^{2}$ M., DE CERTEAU. A escrita da história. Rio de Janeiro: Forense Universitária, 1982, passim. 
abordagens, e à pesquisa histórica cabe - seja qual for sua vertente analítica, hermenêutica ou heurística - buscar não ferir as lógicas próprias das sociedades que estuda, para tal:

\begin{abstract}
... recusando-se a fazer uma leitura ingênua e androcêntrica da documentaçáo supérstite, tanto em termos de sua produção quanto de sua transmissão, cruzando informaçôes de documentos diversos, formulando questóes distintas das tradicionais, de modo que o que antes parecia um "silêncio" das fontes surja como sonoro e pleno de informaçóes, sabendo-se que, na história, as diferenças de sexo têm significações diversas, e a pesquisa precisa trazer à luz essas variaçóes, determinar suas modalidades, seus campos, seus períodos ${ }^{3}$.
\end{abstract}

Os estudos de gênero vêm contribuindo com importantes aportes que nos permitem estudar como essas categorias - ser homem, ser mulher - são elaboradas, e como suas representaçóes se consolidam e se desenvolvem, fixando identidades sexuais que agem sobre os seres humanos, tomados individual e coletivamente, permitindo, do mesmo modo, escapar à cesura rigorosa e sobrevalorizada em estudos de história cultural entre homens e mulheres nas sociedades. Isso porque,

O gênero é, por assim dizer, o "sexo social", ou a diferença dos sexos construída socialmente, um conjunto dinâmico de práticas e de representaçóes, com atividades e papeis assignados, atributos psicológicos, um sistema de crenças. O sexo é percebido como um invariante, enquanto o gênero é variável no tempo e no espaço, a masculinidade e a feminilidade ser homem ou ser mulher ou ser considerado(a) como tal - não tendo a mesma significação em todas as épocas e em todas as culturas ${ }^{4}$.

Outras premissas norteiam nossas análises, dentre as quais destacamos as teses de Judith Butler (1990), e com esta base vemos o gênero como "performativo", ou seja, constituindo uma identidade proposta por um processo político e educacional, entendendo-o como uma construção social,

3 S., BOEHRINGER; V., SEBILLOTTE CUCHET (org.) Hommes et femmes dans l'Antiquité grecque et romaine. Le genre: méthode et documents. Paris : Armand Colin, 2011, p.19.

${ }^{4}$ F., THÉBAUD. Écrire l'histoire des femmes. Paris : ENS Éditions, 1998, p.114. 
culturalmente contingente, e não como uma concretização de uma distinção "biológica", e assumindo que "verdades" sobre as diferenças entre homens e mulheres vão sendo enraizadas no discurso e nas práticas sociais e culturais ${ }^{5}$. As sociedades designam atribuiçóes sexuais - ou sexuadas - e distinguem o que é masculino e o que é feminino, e tais características, seus discursos e práticas, veiculam conteúdos e normatizaçóes de geração em geração, passando a ser considerados "naturais" e "atemporais" ${ }^{\text {, }}$ e as diferenças - que certamente existem entre os seres humanos, entre homens e mulheres, entre homens e homens e entre mulheres e mulheres - tornam-se polarizadas a partir de um processo social, educativo, pois "homens e mulheres não são categorias a priori de si mesmos, $e$ as caracteristicas que lhes são atribuidas - subsumidas nos termos

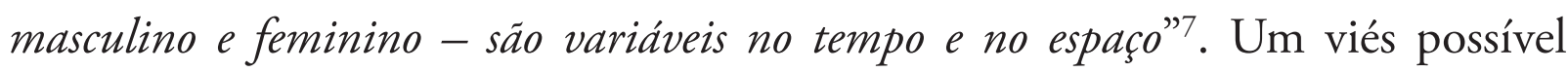
para a análise de gênero nas sociedades é:

Comparar os lugares respectivos assignados a homens e a mulheres num contexto comparável, interrogando-se sobre a permanência do que é apresentado como "natural" pelos discursos, estudando os processos sociais e culturais que levam a apresentar tal e qual prática como sendo "conforme a natureza”, ou seja, não estudar uma ordem "normal”, e sim uma ordem "normalizada".

Um dos mecanismos mais importantes para a construção das diferenças de gênero é a religião. As religiōes dizem respeito não apenas a sentimentos ou percepçóes individuais, mas aos grupos sociais, sendo um dos principais fatores que instituem, consolidam e mantêm a coesão e o ordenamento social, representando-os como uma ordem sagrada ${ }^{9}$, caracterizada

${ }^{5}$ J., BUTLER. Gender Trouble: Feminism and Subversion of Identity (Thinking Gender) New York: Routledge, 1990, p.25.

${ }^{6}$ J., BUTLER. Gender Trouble: Feminism and Subversion of Identity (Thinking Gender) New York: Routledge, 1990, passim.

7 S., BOEHRINGER; V., SEBILLOTTE CUCHET (org.) Hommes et femmes dans l'Antiquité grecque et romaine. Le genre: méthode et documents. Paris: Armand Colin, 2011, p.11.

${ }^{8}$ Ibidem, p.19.

${ }^{9}$ W.E., PADEN. Sacrality as Integrity: "Sacred Order" as a Model for Describing Religious Worlds. In: T.Q., INDINOPULOS; E.A., YONAN (ed.). The Sacred and its Scholars: Comparative Methodologies for the Study of Primary Religious Data. Leiden: Brill, 1996, passim. 
por uma constante luta entre a manutenção de determinada ordem e sua potencial violação, na qual o "sagrado" é visto como uma entidade ou fenômeno sobrehumano que se "manifesta" no mundo, sacralizando a própria ordem social, cujo conteúdo é sempre culturalmente definido. William Paden argumenta que a distinção entre ordem e "antiordem", na qual as religióes se fundamentam é "relacionada com necessidades humanas comuns de autopreservação, defesa do território, honra, tradição, autoridade, lei, laços e papeis sociais, e outras formas de status" ${ }^{\prime 1}$. Como Paden destaca, a sacralidade não é construída como um "além”, mas como o modo pelo qual uma ordem social específica é consolidada ou mantida intacta ${ }^{11}$.

Ursula King chama a atenção para a importância da religiáo como fator central na construção e na dinâmica da relação entre os gêneros:

As religióes proveem mitos e símbolos de origem e de criação, frequentemente oferecem narrativas de redenção e de salvação (...). Religiōes criaram e legitimaram os gêneros, reforçaram-nos (...). Religiấo e gênero não são apenas análogos, existindo paralelamente uma ao outro no mesmo nível. Tampouco são duas realidades independentes que são simplesmente reunidas numa comparação simples, pois os padrões dinâmicos do gênero estão profundamente arraigados nas diversas religióes, fundidos $\mathrm{e}$ interestruturados nas experiências religiosas. Este arraigamento significa que o gênero é inicialmente difícil de identificar e separar de outros aspectos da religião ${ }^{12}$.

A diferenciação sexual parece ter sido marcada por meios complexos na sociedade romana e o estudo dos rituais e práticas religiosas em geral pode ser um caminho possível para sua análise. Na performance dos rituais romanos, John Scheid observa que:

\footnotetext{
${ }^{10}$ Ibidem, p.06.

${ }^{11}$ Ibidem, p.05.

12 U., KING. Religion and Gender: Embedded patterns, interwoven frameworks. In: T.A., MEDDE; M.E., WIESNER-HANKS. (ed.). A Companion to Gender History. New Jersey: The Blackwell Publishing Ltd. 2004, p.71.
} 
... gestos e comportamentos construíam representaçóes e enunciados sobre o sistema das coisas e de seres, enunciados que, à maneira de atos performativos, podiam se tornar uma realidade na consciência daqueles que celebravam tais ritos e daqueles que os assistiam. E, como sempre, na reconstrução dos enunciados formulados pelos gestos - e especialmente aqueles transmitidos por fontes indiretas -, todos os detalhes são importantes ${ }^{13}$.

Os rituais romanos apresentavam homens e mulheres como categorias distintas e, numa abordagem de gênero, busca-se entrever o relacionamento entre as representações de elementos masculinos e femininos nessas performances que estabeleciam fronteiras entre o que é ser homem e o que é ser mulher. $\mathrm{O}$ estudo do calendário de ritos, por exemplo, pode nos prover um exemplo dessa complexidade. Mas é preciso notar que o endereçamento dos rituais a divindades sexuadas e a aparente restrição dos mesmos a cada um dos "polos sexuais" da urbs não implica a exclusão nem a ausência do outro no ritual, isso porque a documentação supérstite - neste caso, os discursos textuais - e a própria historiografia muitas vezes parecem ter exagerado a exclusividade das personagens sexuais, levando a uma ilusão de ótica no que tange ao estudo dos papeis de gênero nos rituais romanos.

As crenças e práticas religiosas têm um papel decisivo na formação das identidades, sejam individuais ou coletivas e, no caso específico da sociedade romana antiga, os ordenamentos jurídico, familiar, político etc., têm sua base no complexo sistema religioso romano. A religiáo dá sentido e cria um mundo ordenado para os seres humanos, ensinando-lhes seus lugares, delineando suas imagens e seus corpos, formando sua compreensão de mundo, de poder, de autoridade, veiculando normas e valores, e incutindo em mulheres e homens seus papeis sociais. Não é excessivo, portanto, reiterar a centralidade dos festivais na religiáo romana. Os festivais latinos e romanos ordenavam as

13 John, SCHEID. An introduction to Roman Religion. Bloomington, Indianapolis: Indiana University Press, 2003, p.184. 
atividades das comunidades ao longo do ano, e forneciam uma estrutura sólida para as práticas religiosas e sociais. Rituais religiosos devem ser interpretados como complexos sistemas cognitivos. Vemos, nos rituais, uma mescla de conhecimento religioso, conhecimento ritual e conhecimento simbólico. E, segundo Michel Foucault:

O ritual define a qualificação que devem possuir os indivíduos que falam (e que, no jogo de um diálogo, devem ocupar determinada posição e formular determinado tipo de enunciados); ele define os gestos, os comportamentos, as circunstâncias e todo o conjunto de signos que deve acompanhar o discurso; fixa, enfim, a eficácia suposta ou imposta quanto às palavras, seu efeito sobre aqueles aos quais se dirigem, os limites de seu valor repressivo ${ }^{14}$.

Para nossos propósitos, o calendário, portanto, é um documento fundamental. Os calendários podem ser vistos como instrumentos de sistematização do tempo social, criando um sistema de coerência cronológica, linear e cíclico, oferecendo pontos de referência permanentes que engajam e coordenam as atividades humanas e os indivíduos no grupo, homogeneizandoos e, além disso, orientando a compreensão de cada um em relaçáo a si mesmo e à comunidade, em relação ao passado, ao presente e ao futuro ${ }^{15}$. No interior do calendário, os rituais marcam a progressão do tempo, criam as rotinas dos grupos humanos e lhes dão solidez e permanência. Rituais ligam indivíduos a grupos, e estes ao passado, projetando o futuro. Em Roma, o calendário era bastante complexo, preservando o grande ciclo agrário e acrescentando uma memória ritualizada da vida cívica, das Kalendas de março às Terminalia, de 23 de fevereiro, que talvez marcassem o fim do ano cívico. Remetemos, dados os limites deste texto, ao excelente artigo de Norma Mendes e Airan Borges para o detalhamento da estrutura geral do calendário romano ${ }^{16}$.

Interessa-nos aqui apresentar uma breve análise de alguns rituais que ocorriam no mês de março - que, no calendário arcaico, era o primeiro mês do

\footnotetext{
${ }^{14}$ Michel, FOUCAULT. A ordem do discurso. Aula inaugural no Collège de France. São Paulo: Ed. Loyola, 1996, p.41.

${ }^{15}$ S.A., TAKÁCS. Vestal Virgins, Sibyls and Matrons. Women in Roman Religion. Austin: University of Texas Press, 2008, p.27.

16 Norma Musco, MENDES; A. S., BORGES. Os calendários romanos como expressão de etnicidade. In: História: Questôes \& Debates, 48/49. Editora UFPR, 2008.
} 
ano, mantendo-se como o marco inicial das festas religiosas romanas (cf. Ovídio, Fasti, II, 50; Varrão, L.L., 6,13), observando rituais nos quais jovens romanos da aristocracia tornavam-se cidadãos de pleno direito e nos quais era estabelecido aquilo que era esperado dos homens, comparando-os a rituais "femininos" que consideramos correlatos, destinados às mulheres das gentes romanas, nos quais aprendiam ou reiteravam seu lugar e seu papel no interior da domus e da familia romana, e suas interaçóes e interrelaçóes que representavam e veiculavam a ordem sagrada romana, capaz de garantir a perenidade da urbs, com base na pax deorum.

A publicação dos calendários em suporte duradouro, contudo, é um fenômeno de fins da República e, especialmente dos reinados de Augusto e Tibério. Há muitas informaçóes sobre as características do calendário romano no início do principado, mas poucas para períodos anteriores. Versóes pintadas, como a de Ancio, anterior à reforma do calendário de Júlio César, e uma do início do século I d.C., de Preneste, com comentários creditados a Verrio Flaco, tiveram de ser reconstituídas pelo uso de outros tipos documentais - fontes literárias, mençóes a datas em inscrições etc. Os Fasti de Ovídio, e.g., formam um poema altamente sofisticado dos festivais, e são um documento precioso para nossa análise. Os calendários latinos são uma fonte importante não apenas para as datas dos principais rituais, mas também para seu conteúdo ${ }^{17}$. Ressaltamos, aqui, que um ciclo anual de festivais públicos regulares, as feriae statiude, é detectado para o período arcaico, marcando sua presença nos calendários posteriores que chegaram até nós, e é um desafio para os pesquisadores identificar permanências e mudanças nesses festivais ao longo do período republicano. $\mathrm{O}$ calendário romano, assim, preserva um bom grau de informações sobre a sequência dos festivais mais antigos ${ }^{18}$. Se não sobreviveram registros literários do período arcaico, os calendários republicanos e do início do principado são documentos que preservaram algumas informaçóes sobre a organização temporal dos festivais da Roma anterior ao século III a.C.

\footnotetext{
${ }^{17}$ R., HAENSCH. Inscriptions as Sources of Knowledge for Religions and Cults in the Roman World of Imperial Times. In: J., RÜPKE (ed.). A Companion to Roman Religion. New Jersey: The Blackwell Publishing, 2007, p.178.

18 John, SCHEID. An introduction to Roman Religion. Bloomington, Indianapolis: Indiana University Press, 2003, pp.41-59.
} 


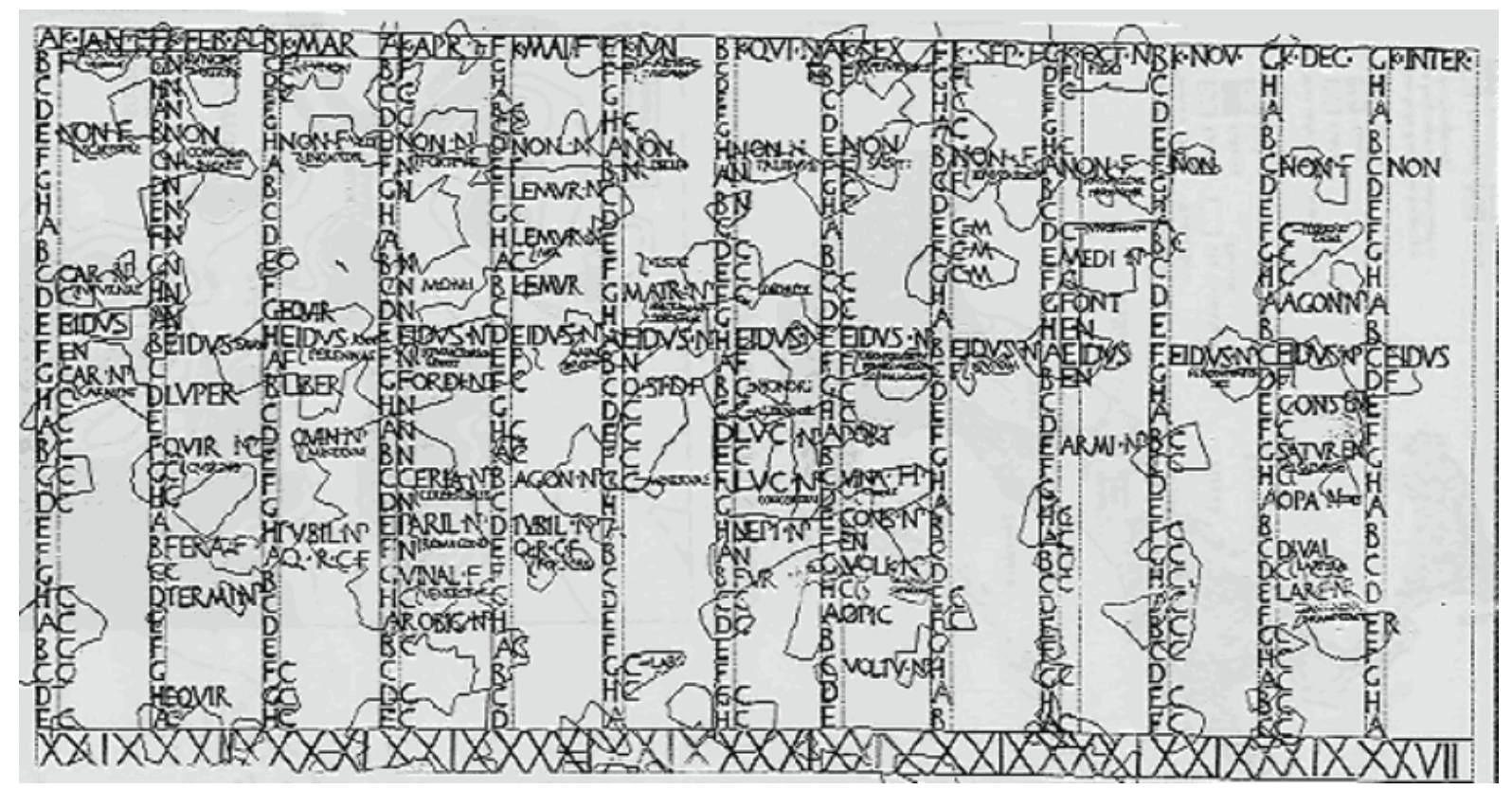

Fasti Antiates maiores, circa 60 a.C. segundo reconstrução de J. Rüpke ${ }^{19}$.

Por sua vez, a maior parte da documentação textual que temos sobre rituais religiosos romanos é formada por escritos do período tardo-republicano e do principado. A exegese literária talvez permita perceber o que determinado autor ou grupo social específico pensava sobre um determinado tema e a projeção de elementos rituais e cultos contemporâneos do autor no passado era algo constante. $\mathrm{O}$ mais extenso texto literário sobre os festivais regulares, o citado poema-calendário de Ovídio, por exemplo, insere-se no contexto da restauratio augustana, e devemos refletir sobre as características da documentação textual e sua utilização nos estudos sobre a religião romana. Certamente, o registro literário nos apresenta tais rituais num momento tardio de seu desenvolvimento, ou mesmo em sua recuperação pela restauratio augustana, mas, ao mesmo tempo, validava novos cultos e práticas inovadoras com referência a antigas tradições religiosas ${ }^{20}$. Desse modo, acreditamos que a análise da documentação literária, mesmo que tardia, pode ser profícua para o estudo dos rituais religiosos romanos. Esses textos trazem, nitidamente, alguns

\footnotetext{
${ }^{19}$ R., HAENSCH. Inscriptions as Sources of Knowledge for Religions and Cults in the Roman World of Imperial Times. In: J., RÜPKE (ed.). A Companion to Roman Religion. New Jersey: The Blackwell Publishing, 2007, p.177.

${ }^{20} \mathrm{~J}$., NORTH. Religion in Republican Rome. In: F.W., WALBANK; A.E., ASTIN; M,W., FREDERIKSEN; R.M., OLGIVIE (ed.). The Rise of Rome to 220 B.C. In: The Cambridge Ancient History. 2 ed, v. VII-2, 1989.
} 
elementos de fundo arcaico (cf. D. Hal. 7, 70, 2-3: tas archaias kai topicas historias), que sobreviveram não fossilizados, ou seja, num contexto dinâmico, pois cada geração reconstituía e ressignificava o ritual e o mito ${ }^{21}$.

O mês de março, dedicado a Marte, protetor do pomerium (o limite sagrado da cidade), e a quem o mito atribuía a paternidade de Rômulo e Remo, era o início do ano agrícola e guerreiro arcaico e, até cerca de fins do século IV a.C., coincidia com o início do ano político, que era encerrado em fevereiro, mês de purificaçóes e expurgos. Interessa-nos, pois, os tempos dos ritos, os agonia, que podemos entrever graças à sua inserção no calendário e que, no mês de março, iniciam o ciclo agrário da reprodução, da manutenção da vida e da guerra. Sua presença no calendário, como feriae statiuae permite-nos situá-los no tempo e destacar sua dimensão simbólica nos grandes ciclos do sistema do calendário romano, fornecendo suas coordenadas lógicas e simbólicas.

Os dados do calendário, cotejados com dados da tradição literária e da tradição jurídica, permitem perceber tanto as diferenças quanto a complementaridade dos elementos masculinos e femininos na performance e nos destinatários dos rituais romanos no que tange à garantia da ordem social, a manutenção da pax deorum-pax hominum. Percebemos tais ritos conexos no reconhecimento coletivo de sua capacidade reprodutiva e de proteção da comunidade no sistema das festas de março, iniciando-se pelos ritos das Matronalia, nas Kalendas ( $=1^{\mathrm{o}}$ de março), continuando com o ritual denominado ancilia mouent em 9 de março, os ritos da pouco conhecida Anna Perenna, nos Eidus (=15 de março) até o Quinquatrus e o Turbilustrium (= 23 de março) e a partida dos homens para a guerra $(Q R C F$, no dia seguinte, ou seja, em 24 de março), sacralizando a nova geração da cidade, distinguindo moças e rapazes, e certificando que estavam prontos para desempenhar os papeis que a sociedade romana assignava a umas e outros, de modo coerente com o comportamento coletivo desejado.

Observemos uma síntese da concatenação dos ritos masculinos e femininos do mês de março:

${ }^{21}$ Claudia, BELTRÃO. A Religiáo na urbs. In: Norma Musco, MENDES; Gilvan Ventura, SILVA (org.) Repensando o Império Romano. Rio de Janeiro: Mauad X, 2006, passim. 


\begin{tabular}{|c|c|c|c|c|}
\hline Dia & Festival & Oficiante & Período & Definição \\
\hline $1 K A L$. & MATRONALIA & Feminino & Diurno/noturno & $\begin{array}{l}\text { As Vestais acendiam } \\
\text { o fogo no templo de } \\
\text { Vesta - novo ano } \\
\text { religioso. } \\
\text { Homenagens das } \\
\text { Vestais, das matres e } \\
\text { das parturientes a } \\
\text { Iuno Lucina, no } \\
\text { Esquilino. Oraçóes } \\
\text { dos patres no } \\
\text { interior das domi; } \\
\text { banquete ritual das } \\
\text { matronas para seus } \\
\text { escravos. }\end{array}$ \\
\hline 9 & ANCILIA MOVENT & Masculino & Diurno & $\begin{array}{l}\text { salis faciunt in } \\
\text { Comitium - dança } \\
\text { dos sálios no forum, } \\
\text { portando os ancilia; } \\
\text { procissáo na Via } \\
\text { Sacra. Sacrifício e } \\
\text { banquete para } \\
\text { Marte. }\end{array}$ \\
\hline 14 & EQVIRRIA & Masculino & Diurno & $\begin{array}{lr}\text { Sacrifício } & \text { para } \\
\text { Marte, corrida de } & \\
\text { cavalos } & - \\
\text { consagraçáo } & \text { dos } \\
\text { animais. } & \end{array}$ \\
\hline 15 EID. & ANNA PERENNA & $\begin{array}{l}\text { Feminino/ } \\
\text { Masculino }\end{array}$ & Noturno & $\begin{array}{llr}\text { Início } & \text { do } & \text { ano } \\
\text { agrícola. Ritos no } & \text { no } \\
\text { bosque de } & \text { Anna } \\
\text { Perenna } & & \text { (Via } \\
\text { Flaminia), } & \text { com } \\
\text { danças e libaçóes de } \\
\text { vinho e a presença } \\
\text { de homens. }\end{array}$ \\
\hline 17 & $\begin{array}{l}\text { LIBERALIA } \\
\text { AGONALIA }\end{array}$ & Masculino & Diurno & $\begin{array}{lr}\text { Jovens } & \text { romanos } \\
\text { recebiam } & \text { a } \quad \text { toga }\end{array}$ \\
\hline
\end{tabular}




\begin{tabular}{|c|c|c|c|c|}
\hline & $\begin{array}{l}\text { (AGONIVM } \\
\text { MARTES) } \\
\text { ARMILVSTRIVM }\end{array}$ & & & $\begin{array}{l}\text { uirilis, iniciando os } \\
\text { tirocinia militae e } \\
\text { fori, enquanto suas } \\
\text { mães faziam } \\
\text { sacrifícios a Liber } \\
\text { Pater. } \\
\text { Sacrifícios em hora } \\
\text { de Marte (realizados } \\
\text { pelo rex, depois } \\
\text { pelos flamines de } \\
\text { Marte). } \\
\text { Dança dos sálios, } \\
\text { consagração das } \\
\text { armas no Campo de } \\
\text { Marte. }\end{array}$ \\
\hline 19 & QVINQVATRVS & \multirow[t]{4}{*}{ Feminino } & \multirow[t]{4}{*}{$?$} & \multirow{5}{*}{ 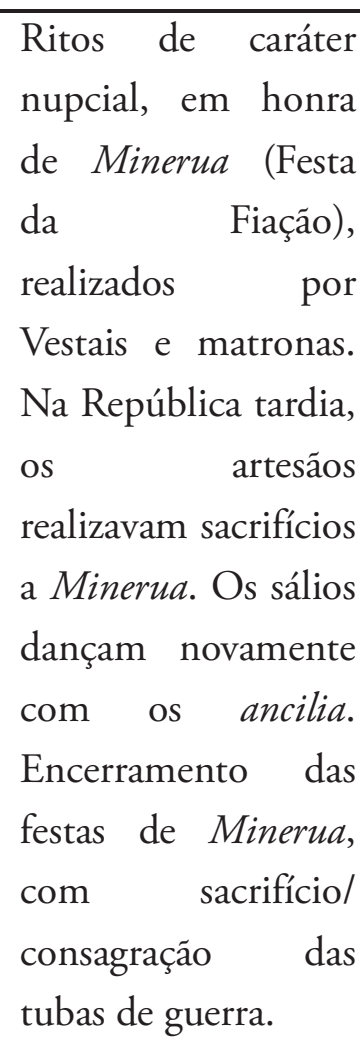 } \\
\hline 20 & QVINQVATRVS (?) & & & \\
\hline 21 & QVINQVATRVS (?) & & & \\
\hline 22 & QVINQVATRVS (?) & & & \\
\hline 23 & $\begin{array}{l}\text { QVINQVATRVS (?) } \\
\text { TVRBILVSTRIVM }\end{array}$ & Masculino & Diurno & \\
\hline 24 & $\begin{array}{l}\text { Q.R.C.F (quando rex } \\
\text { comitiauit fas) }\end{array}$ & Masculino & Diurno & $\begin{array}{l}\text { classis in procinctu - } \\
\text { partida do populus } \\
\text { (homens } \\
\text { mobilizáveis) para a } \\
\text { guerra. }\end{array}$ \\
\hline
\end{tabular}

Nas Kalendas, em $1^{\circ}$ de março, as vestais acendiam um novo fogo no aedes Vesta, no forum Romanum, simbolizando o início do novo ciclo anual. Em seguida, 
ofereciam parte de seus cabelos no templo de Iuno Lucina, no Esquilino (Plínio, $H N$, XVI, 235), o que dava início às festividades das Matronalia para as mulheres romanas. Os ritos da Matronalia no templo eram realizados pelas matronas, sobretudo as que já fossem matres, e pelas parturientes com festas em homenagem a Iuno Lucina, deusa que presidia os partos.

Fanny Dolansky, em artigo recente, reexaminou os ritos da Matronalia à luz das pesquisas de gênero atuais, chamando a atenção para a interdependência dos distintos componentes da domus romana - matrona, paterfamilias, e a própria familia ${ }^{22}$ - na sequência e na performance dos rituais que compunham este festival, celebrados no templo de Juno Lucina e no interior das casas aristocráticas. Dentre os ritos, destacam-se os sacra para Juno Lucina, as oraçóes dos maridos pela saúde de suas mulheres e pela concórdia do casal, e o banquete servido pelas matronas aos escravos na domus, e a autora observa a contribuição ritual de todos os celebrantes e demais participantes da festividade, cujo sentido, conclui, é o bem-estar da domus tomada em conjunto, promovendo a integração de seus componentes e reafirmando valores sociais cujo fundamento são as relaçóes de gênero e o status jurídico de seus habitantes. $O$ festival reflete a intrincada relação entre gênero e poder, que tem de ser constantemente renegociada, inclusive no interior da domus. Para a autora, o banquete dos escravos na Matronalia, tradicionalmente associado ao da Saturnalia de dezembro (desta feita, conduzido pelo paterfamilias) reitera a hierarquia social e jurídica entre senhores e escravos e as relaçóes apropriadas entre as matronae e a escravaria no interior da domus, criando e consolidando a coesão familiar e social. Longe de considerar a vida religiosa de mulheres romanas isoladamente, Dolansky destaca as interrelaçóes de gênero na religião romana. A Matronalia, portanto, mais do que um rito "feminino", é um rito "doméstico".

Os nouendiales de 1 a 9 de março eram iniciados, portanto, com as Matronalia e encerrados com o ritual denominado ancilia mouent, também

\footnotetext{
${ }^{22}$ A família patriarcal romana é um agrupamento de pessoas livres e não livres (famuli, escravos, de onde deriva o nome familia: ERNOUT; MEILLET, s.v. familia), que implica propriedade e patrimônio.
} 
conhecido como salis faciunt in Comitium, que iniciava o ciclo ritual dos sálios, quando este colégio sacerdotal arcaico dançava, entoava hinos arcaicos e movia os escudos sagrados (ancilia), prenunciando a campanha guerreira da primavera. Raymond Bloch estudou detalhadamente o ritual, as danças, as descriçóes dos ancilia e as vestes desses sacerdotes no mês de março, mesclando dados literários, inscriçôes e duas representaçôes visuais dos escudos ${ }^{23}$, e levantou questôes sobre o significado dos ritos dos sálios: um ritual de magia imitativa? Um ritual que visa à salvaguarda da cidade e sua prosperidade, incentivando nos jovens o ímpeto guerreiro e afugentando os inimigos? Um rito arcaico de purificação dos campos, cujo sentido se perdeu para os romanos da República tardia? Já Henri Le Bonniec, analisando aspectos religiosos da guerra em Roma, vincula tais rituais ao início do calendário de guerra. Le Bonniec defende que a dança principal dos sálios ocorria em 19 de março, dia do festival do Quinquatrus, no período arcaico um festival em honra a Marte e, à época de Cícero, a Minerva ${ }^{24}$. Com base na observação dos Fasti Antiates maiores, e a partir do destaque dado pela literatura romana ao rito dos ancilia mouent que culminava no banquete ritual para Marte (cf. Ovídio. Fasti, III, 878; Suet. Claudio, 33), tendemos a destacar a própria sequência das danças iniciada no festival ancilia mouent e culminando no Turbilustrium, véspera da partida (então simbólica) dos homens mobilizáveis para a guerra.

Segundo Filippo Coarelli, os sálios eram concebidos como "filhos do rex", enquanto as vestais eram suas "filhas", antes de serem vinculadas ao pontifex maximus ${ }^{25}$. E Plínio o Velho diz que a iniciaçáo dos jovens equites, em seu tempo, mantinha elementos do ritual e do vestuário sálico ( $H N, \mathrm{XV}, 134)$.

\footnotetext{
${ }^{23}$ R., BLOCH. Sur les danses armées des Saliens. In : Annales E.S.C. $13^{\mathrm{e}}$ année, 4, 1958.

${ }^{24}$ H., LE BONNIEC. Aspects religieux de la guerre à Rome. In : Jean-Paul, BRISSON (org.). Problèmes de la guerre à Rome. Paris: Mouton \& Co., 1969, p.102. Claudia, BELTRÃO. Guerra, direito e religiấo na Roma tardo-republicana. In: Pedro Paulo, FUNARI; Margarida Maria de, CARVALHO; Cláudio U., CARLAN (Org.). História Militar do Mundo Antigo. História Militar do Mundo Antigo - Guerras e Representaçóes. v.2. São Paulo: Fapesp, 2012, passim.

${ }^{25}$ F., COARELLI. Il foro boario. Dalle origini alla fine della Repubblica. Roma: Quasar, 1988, pp.388,416; M., BEARD; J.A., NORTH; S.R.F., PRICE. Religions of Rome. v. 1 (A History); v. 2 (A Sourcebook). Cambridge: Cambridge University Press, 1998, pp.12-15.
} 
Para Mario Torelli ${ }^{26}$ e Coarelli ${ }^{27}$, os ritos dos sálios vinculavam-se ao triunfo arcaico, anterior a um "período etrusco" ${ }^{28}$ da urbs, e o percurso de sua dança seguia a Via Sacra, percurso que se manteve no triunfo pós-etrusco. Em Roma, o locus dos sálios era a Regia, onde custodiavam os ancilia, os escudos sagrados (Fest, $439 \mathrm{~L}$ ), como as vestais custodiavam o fogo sagrado da urbs no aedes Vesta ${ }^{29}$.

Seguia-se o festival das Equirria, de 14 de março, com sacrifício para Marte e a corrida de cavalos na qual os animais eram consagrados para a guerra no Campo de Marte, culminando nos Idos de março, que no período arcaico aparentemente coincidia com a primeira lua cheia do ano agrícola, com as festas no bosque de Anna Perenna, cujos elementos propiciatórios da fertilidade são notórios: "Aflui o povo, e por cima dessas relvas se espalham a beber; cada homem se deita com sua parceira ao ar livre" (Ovídio, Fast. III, 525-526), "para que o ano se complete com alegria" 30 (Macróbio, Sat, I, 12,6).

Em 17 de março, no ritual das Liberalia, jovens romanos da aristocracia eram conduzidos por seus pais ou tutores ao forum Romanum, enquanto suas mães sacrificavam a Liber Pater por seus filhos. Os rapazes trajavam, pela primeira vez, a toga uirilis, abandonando a bulla e as vestes de criança, numa espécie de "rito de passagem" da criança ao cidadáo, com seu caráter de iniciação guerreira, celebração e espetáculo. $\mathrm{O}$ ritual apresentava uma grande pedagogia coletiva do tempo da guerra e da reproduçáo da comunidade ${ }^{31}$. O

${ }^{26}$ M., TORELLI. Riti di passagio maschili di Roma Arcaica. In: MEFRA. Mélanges de l'École française de Rome. Antiquité, t. 102, n. 1, 1990, p.416.

${ }^{27}$ F., COARELLI. Il foro boario. Dalle origini alla fine della Repubblica. Roma: Quasar, 1988, p.98. ${ }^{28}$ Para nossos propósitos neste artigo, as discussóes recentes sobre a existência de um "período etrusco” na Roma monárquica são irrelevantes. Importa notar, contudo, que o sacerdócio dos sálios - assim como o sacerdócio de Vesta - não é exclusividade romana, tampouco uma criação romana. Colégios semelhantes e correlatos foram detectados em cidades do Lácio e da Etrúria.

${ }^{29}$ P., HORVAT. O Templo de Vesta e a ideia romana de centro do mundo. Phoînix 13, 2007.

30 A., MASTROCINQUE. Late antique lamps with defixiones. In: GRBS. Greek, Roman, and Byzantine Studies, 47, 2007, passim.

31 Remetemos a um artigo que publicamos em 2007, no qual apresentamos uma análise do tirocinium fori no que tange à formação do "bom cidadáo romano", o uir bonus, em fins da República e nas primeiras décadas do principado Apresentamos, então, o forum Romanum como um lugar privilegiado para o estabelecimento do significado cultural de gênero na Roma antiga, um espaço ordenado para a realizaçáo e desenvolvimento dos negócios "masculinos": os discursos 
ritual era, simultaneamente, político e religioso, e ressaltamos a importância de se ultrapassar as rígidas distinçóes modernas entre política e religião, por não serem adequadas à pesquisa da sociedade romana antiga ${ }^{32}$. No mesmo dia seguia-se o Armilustrium, quando os sálios novamente dançavam e as armas das legiōes eram consagradas, e ocorriam os sacrifícios e os banquetes das Agonalia, em honra de Marte (agonium Martes).

O ciclo de março continuava com o festival do Quinquatrus, entre 19 e 23 de $\operatorname{març}^{33}$, com ritos de caráter nupcial em honra de Minerua, deusa que ensinava as meninas a fiar a lá (Varrão, L.L. VI, 14), concluindo com o Turbilustrium de 23 de março, também dedicado a Minerua, protetora das tubas de guerra, e a partida do populus para a guerra (classis in procinctu) em 24 de março, designada pela fórmula Q.R.C.F: quando rex comitiauit fas, de cunho arcaico, remetendo a um tempo no qual o rei chamava os comitia para a guerra.

$\mathrm{Na}$ organização dos ritos no calendário, vemos a intervenção da comunidade no comportamento de mulheres e homens, criando o "homemguerreiro" e a "mulher-mãe", e remetemos, por exemplo, aos excelentes estudos de Torelli sobre o tema, nos quais destacou a correspondência entre as vestais e os sálios, que perdurou nas vestes matrimoniais das primeiras e no armamento dos segundos ${ }^{34}$. As festas de março preparavam o mundo humano para a reproduçáo e a partida para a guerra, celebrando a capacidade geradora dos

políticos, o recenseamento dos cidadãos, os tribunais etc. ali tinham seu lugar, e destacamos a formação para a oratória, apropriada aos homens, como um dos elementos que os distinguiam das mulheres, de quem era esperado o silêncio. Cícero, no Brutus e no Pro Caelio, demonstra como esse processo educativo masculino era estruturado, no qual o forum Romanum surgia como o locus do bom orador e do bom cidadáo, criando e consolidando a identidade do uir bonus. Claudia, BELTRÁO. Tirocinium fori: o orador e a criação de "homens" no forum romanum. Phoînix 13. Rio de Janeiro, 2007, passim.

${ }^{32}$ Claudia, BELTRÃO. A Religião na urbs. In: Norma Musco, MENDES; Gilvan Ventura, SILVA (org.) Repensando o Império Romano. Rio de Janeiro: Mauad X, 2006, passim.

${ }^{33}$ Em calendários mais antigos, o festival ocorria apenas em 19 de março, e é assim que a data do festival surge em Varrão. Ovídio (Fast, III, 809 ss), contudo, apresenta cinco dias de festival, incluindo festividades de artesãos em Roma, o que talvez se explique por seu helenismo marcante, apresentando Minerua-Atená Partenos como divindades similares.

${ }^{34}$ M., TORELLI. Lavinio e Roma. Riti iniziatici e matrimonio tra archeologia e storia. Roma: Quasar, 1984; M., TORELLI. Riti di passagio maschili di Roma Arcaica. In: MEFRA. Mélanges de l'École française de Rome. Antiquité, t. 102, n. 1, 1990, passim. 
novos cidadãos. Esses rituais ligavam mulheres e homens a lugares, vestuários e comportamentos específicos, veiculando imagens, gestos e representações que reforçavam e garantiam a confiança no ritual, na ordem social e nas diferenças de gênero, promovendo o engajamento dos indivíduos às normas da vida comunitária.

Percebemos tais ritos, em seu desenvolvimento no calendário, como representaçôes simbólicas do ordenamento familiar, social e político romano, incluindo uma forte polarização entre os cultos "masculinos" e os cultos "femininos" em rituais conectados e complementares nas festas de março. O que era definido e desejado como aspecto "feminino" da urbs surgia nas festas das Matronalia, de Anna Perenna e no Quinquatrus, para além de uma participação direta das vestais em rituais "masculinos"35. O destino social assignado às mulheres romanas era o da reprodução biológica e o cuidado da domus, e seu processo de formação também desenvolveu uma pedagogia social pública, apesar de não tão nítida (para nós) quanto a formação "masculina”. Ao uir bonus uma dupla tarefa social era assignada: a guerra e a condução dos negócios públicos, e os ritos masculinos enfatizavam a pedagogia guerreira, com a crescente ênfase, a partir do século III a.C., na formação retórica ${ }^{36}$, mas seu aspecto guerreiro manteve-se ao longo da história religiosa romana.

A propriedade do populus e sua manutenção surgem como o resultado de campanhas guerreiras, em que terras e pessoas eram conquistadas e/ou integradas, e, internamente ao grupo social, como resultado da proteção e da manutenção da domus romana, nas quais se inseriam a produção e o cuidado de filhos legítimos, a harmonia entre o casal principal e as boas relaçôes, hierarquicamente conduzidas, entre senhores e dependentes.

Daí a importância social das festas do ciclo de março, criando identidades de gênero e atribuindo a cada uma das partes dessa sociedade

35 M., BEARD; J.A., NORTH; S.R.F., PRICE. Religions of Rome. v. 1 (A History); v. 2 (A Sourcebook). Cambridge: Cambridge University Press, 1998, passim; S.A., TAKÁCS. Vestal Virgins, Sibyls and Matrons. Women in Roman Religion. Austin: University of Texas Press, 2008, passim; A., STAPLES. Quand faire, c'est croire. Les rites sacrificiels des romains. Paris: Aubier, 2005, passim.

${ }^{36}$ Claudia, BELTRÃO. Tirocinium fori: o orador e a criação de "homens" no forum romanum. Phoinix 13. Rio de Janeiro, 2007, passim. 
polarizada seu lugar sacralizado. Nessa sociedade androcêntrica e guerreira, as mulheres, contudo, desempenhavam um importante papel na manutenção da ordem romana, garantindo o ordenamento social desejado. Em março, vemos “... a própria organização social expressa nos mitos, nos símbolos, nos sistemas de correspondências, (...) a série homogênea dos postulados relativos à ordem do mundo e da sociedade" ${ }^{37}$. Desse modo,

Historicizar a diferença sexual não é fazer a história das mulheres como uma história à parte: é considerar que o conhecimento da história das mulheres permite avançar no conhecimento da história das sociedades de um modo mais amplo; é, também, propor uma história que afirma que todas as sexualidades e todas as identidades, individuais e coletivas, revelam elaboraçôes sociais e culturais ${ }^{38}$.

A religio romana, portanto, é um dos principais fundamentos do regramento romano de gênero, e teve um impacto direto em suas principais instituiçóes, e as "mulheres silenciosas de Roma"39 - ou silenciadas pela literatura romana e pela historiografia moderna - envolviam-se ativamente na construção da ordem sagrada, garantindo a estabilidade da dinâmica social romana e de sua ideologia.

${ }^{37}$ Marc, AUGÉ (org.) A construção do mundo (religião, representaçôes, ideologias). Lisboa: Ediçóes 70, 2000, p.15.

38 S., BOEHRINGER; V., SEBILLOTTE CUCHET (org.) Hommes et femmes dans l'Antiquité grecque et romaine. Le genre: méthode et documents. Paris : Armand Colin, 2011, p.12.

${ }^{39}$ Moses, FINLEY. As mulheres silenciosas de Roma. In: Moses, Finley. Aspectos da Antiguidade. Lisboa: Ed. 70, 1990, passim. 